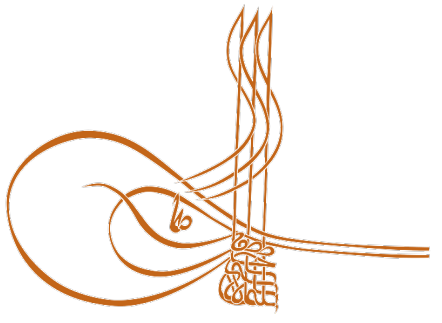

www.turkishstudies.net/language
Turkish Studies - Language and Literature

eISSN: $2667-5641$

Research Article / Araștırma Makalesi

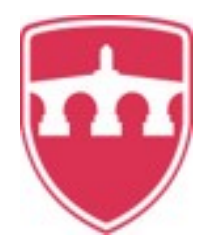

INTERNATIONAL

BALKAN

UNIVERSITY

Sponsored by IBU

\title{
Sezai Karakoç'un Nesir Dilinde Gelenek ve Tesir
}

Tradition and Influence in Sezai Karakoç's Prose Language

\author{
Kemal Şamlıŏlu*
}

\begin{abstract}
This article aims to describe and evaluate Sezai Karakoç's thoughts on tradition in his prose writings on the axis of civilization with distinctive aspects. In this context, considering Karakoç's ideas about tradition in the prose language as well as the poetry language, the design effect of this phenomenon from the past to the future will not be overlooked. Because tradition with its dynamic side is considered as a means of opportunity for Sezai Karakoç rather than a frozen pile of information. Considering the taxonomy of importance in the main character of civilization, the basic principles representing the pillars of the Islamic civilization, Karakoç will be referred to as an artist who tries to show us the background of poetry, thought and the struggle of ideas, by placing the tradition at the core of this field of value. But especially the ones he wrote in prose language are important in terms of making epistemological description of the tradition and pointing out the problem areas. In this sense, the tradition that Karakoç pointed out in the prose language also has a remarkable place and influence in the context of supplying and building generations with its dimension of influence. The inspiration of tradition, which has been able to create a space of value from exile to the deprivation of Mary, to Jerusalem, to Mecca, to Istanbul, turns the idea of a solution to a civilization fed from the same dream. Considering such a perspective, Karakoç puts all humanity and universal degeneration out of the idea of tawhid as opposed to the idea of tawhid while establishing the principle on the phenomenon of tradition and resurrection. Therefore, this study aims at a search on which historical framework Karakoç handles the tradition and how it connects with modern time.
\end{abstract}

Structured Abstract: Sezai Karakoç, one of the artists who find tradition and what he has accumulated, sees tradition as a departure point in his works. When it comes to tradition as the determining factor in Karakoç's poems, the concepts of religion and civilization also appear spontaneously in the boundaries of thought. The establishment of the circle of civilization and determination of the boundaries of this circle with religion and metaphysics are essential for Sezai Karakoç for the absolute domain of tradition. Karakoç sees metaphysics as an important principle and understanding in the cultural memory of society. In this context, the most important area of influence in Karakoç's poems has been metaphysics. A alienation and difficulty of definition that will be experienced in metaphysics will cause the identity of civilization to not be originally established. The refraction on the concept of metaphysics will disrupt the belief in God and the Hereafter and bring the problem

\footnotetext{
* Dr., Ankara Hacı Bayram Veli Üniversitesi

Dr., Ankara Haci Bayram Veli Üniversity

ORCID 0000-0003-4765-5592

ksamlioglu@hbv.edu.tr

Cite as/ Atıf: Şamlığlu, K. (2020). Sezai Karakoç’un nesir dilinde gelenek ve tesir, Turkish Studies - Language, 15(1), 397-403. https://dx.doi.org/10.29228/TurkishStudies.40555

Received/Geliş: 14 January/Ocak 2020

Accepted/Kabul: 25 March/Mart 2020

Checked by plagiarism software

Copyright à INTAC LTD, Turkey 
of centralization of the world to a factual value as a secular circle. In this context, religion can be transformed into a ritual of worship by imprisoning in a secular space, and in the framework of the separation of worship from the other world. Karakoç thinks that those who cannot understand the hereafter are also difficult to understand this world. According to Karakoç, if the mind loses its ultra-physical belief, it remains dragged in the secular space. If the window of the soul towards God is not wanted to be seen once, the human will not be able to avoid rolling into much bigger problems than the window of mind and heart. Karakoç, who thinks that the people who have lost this point of view despite being at the center of the physical life are the poor, expresses that the Renaissance has deserted the soul of man.

Karakoç sees Tanzimat as the great destruction period of traditional continuity. According to Karakoç, together with Tanzimat, the main owners of this destruction, who belittled their literature, who thought that our literature was the obstacle to being civilized, and that replaced the ancient values of our literature. Revolutionary movements under the name of modernization made itself felt in the democratization of society in the political sense, and in the cultural change, literature and rhetoric that constitute the other part of this process in the social sense. While Karakoç interprets the breaking of tradition that started with the Tanzimat process through the poetry rhetoric, he emphasizes that this is a slaughter. Karakoç thinks that the real source of our poverty in literature is Tanzimat. The main goal of the founding will of Tanzimat literature, which has the opportunity to develop with the claim of innovation, is the idea of displacing the images of innovation developed within our classical literature. Tanzimat's state administration, which refers to the impressive power of the West in the industry, brings western cultural content to our literature and redefines the aesthetic and epistemological accumulation produced by the tradition with its western concepts and understandings. In this context, Karakoç knows how to stand against the destructiveness of Tanzimat with his dedication to tradition. Karakoç calls out to his society with an attempt to create a modern society of the centralizing power effect and a jealous attitude, which takes its source from East / Islam accumulation and dynamics.

Seeking the concept of nation not on the basis of race but on the unifying feature of history, the poet defines the Turkish nation as a nation that has existed for more than a thousand years. While Karakoç defines the Ottoman period as a nation period, by approaching being a nation to perfection; With its literature, morality, administration, art and many other aspects, it shows it as an unprecedented feature. The poet, who refused the definitions that developed in the West in the 19th century and emerged with the concept of nation in our country, considers the concept of the nation in the Islamic civilization as an organic structure of civilization. Unity of purpose, for a human being who differs from time and space, instead of seeking his ancient roots in a certain religious or cultural basis, instead of seeking the traces of a Hanif humanity that Karakoç followed, Hz. Probhet did not exclude the search for information in Hz. Adam, without approaching the worldly shrines that Hz. Abraham turned away, ignoring the innocence of Mary and points to a civilization different from the pagan bigotry society of the Prophet and a universal and monotheistic value.

The poet argues that one of the basic conditions of being a nation is to have his own literature. Drawing attention to the unity of culture and civilization, Karakoç thinks that civilizations also produce their literatures and this makes the way to become a nation strong. He believes that literature, like culture, should be fed from his own civilization department. Expressing that the source of literature should be formed by the Turkish people's sense, understanding, pain and joys, Karakoç wants to be the subject of his people in all aspects. It is obvious that the transformation from literature to nation and from nation to literature will make the aesthetic values strong. Such a development process will show the benefit not only in our own geography but as the common benefit of all humanity. While Karakoç focuses on the idea that the source of literature should be fed from the truth, he also emphasizes the relationship between the power of literary work and the concept of truth. Karakoç argues that the connection of our literature with the classical period has weakened with the influence of Western originated nationalism. The artist, who has lost his connection with the metaphysical production tradition, is thrown into the field of mental movement of a foreign circle with his western content. This skidding alienates the telling of my story, which classic poetry has accumulated in our literature.

Keywords: New Turkish Literature, Tradition, Civilization, East, West, Creative.

Öz: Bu makale, Sezai Karakoç'un nesir yazılarında geleneğe ilişkin düşüncelerini uygarlık ekseninde, ayırt edici yanlarla tarif ve değerlendirme amacı taşır. Bu bağlamda Karakoç'un şiir dilinin yanı sıra nesir dilinde de geleneğe ilişkin fikirleri dikkate alındığında, söz konusu olgunun geçmişten geleceğe dizaynedici etkisi

Turkish Studies - Language, 15(1) 
gözden kaçmayacaktır. Çünkü dinamik tarafıyla gelenek, donmuş bir bilgi yığını olmaktan çok Sezai Karakoç için imkân vesilesi sayılır. İslâm medeniyetinin sacayaklarını temsil eden temel prensiplerin uygarlığın ana karakterindeki önem taksonomisi düşünüldüğünde Karakoç, geleneği bu değer alanının çekirdeğine yerleştirerek çağımız adına şiirin, düşüncenin ve fikir mücadelesinin arka planını bize göstermeye çalışan bir sanatkâr olarak anılacaktır. Elbette Karakoç, poetikasında geleneğin bütün bir medeniyet dairesi için pratik uzantılarını şiir diline taşıyabilmiş bir sanatkârdır. Fakat özellikle nesir hâlinde kaleme aldıkları da geleneğe ait epistemolojik tanımlama ve sorun alanlarına işaret etmesi bakımından önemlidir. Bu anlamda Karakoç'un nesir dilinde işaret ettiği gelenek, aynı zamanda tesir boyutuyla nesilleri ikmal ve inşa etmek bağlamında dikkate değer bir yere ve etkiye sahiptir. Sürgün olmaktan Meryem'in masumiyetine, Kudüs'e, Mekke'ye, İstanbul'a kadar değer alanı oluşturabilmiş geleneğe ait dinamizmin ilham kaynakları, hep aynı çözüm önerisini aynı rüyadan beslenen bir uygarlık fikrine dönüştürür. Karakoç, ilkeyi gelenek ve diriliş olgusu üzerine kurarken karşı düşünceye tevhid fikrinin dışında kalan bütün insanlığı ve evrensel yozlaşmayı koyar. $\mathrm{Bu}$ yazı, Karakoç’un geleneği hangi tarihsel çerçevede ele aldığına ve modern zamanla ne şekilde irtibatlandırdığına dair bir incelemedir.

Anahtar Kelimeler: Yeni Türk Edebiyatı, Gelenek, Uygarlık, Doğu, Batı, Yaratıc1.

\section{Giriş}

Geleneği ve biriktirdiklerini değerli bulan sanatkârlardan biri olan Sezai Karakoç, eserlerinde geleneği kalkış noktası olarak görür. Karakoç'un şiirinin oluşum sürecinde geleneğin belirleyici etkisi olduğu yadsınamaz bir gerçektir. İkinci Yeni şiiriyle aynı dönem ve akım içerisinde değerlendirilen Karakoç’un bu dönemden ve çağcıllarından onu ayrıştıran en önemli yanı da sanatını ifade ediş biçiminde geleneğin önemli bir yer tutmasıdır: "Karakoç'un kurmayı denediği yenilik düşüncesi, asli unsur olarak modern zamana karşı bir değişim yaşamıș ama bu değişim içinde değişmeyen bir ethos özelliğiyle korunmuş gelenek uzantılarından ayrışmamıştır." (Polat, 2018: 256). Dolayısıyla Karakoç'un şiirlerinde belirleyici unsur olarak gelenek konu edilince, din ve medeniyet kavramları da kendiliğinden düşüncenin sınır boylarında belirir. Geleneğin mutlak etki alanı için medeniyet dairesinin kurulması ve bu dairenin sınırlarının din ve metafizik ile belirlenmesi Sezai Karakoç’ta esastır. Metafiziğin kapsayıcılığ medeniyet kurulumu hedefinde olmazsa olmazlardandır. Buna mukabil Karakoç çağımızda metafizik kavramının ters yüz edildiğini düşünür: "Auguste Comte'un üç hal kanunu, metafiziği büyüye, sihre, eski çă̆ kâhinliğine indirgedi; Marksizm ise, dini, bu dar metafizik kavramına, yani Comte'tan ödünç alınan bu görüş çerçevesinde bir kalıba soktu. Üstelik bir de 'yansıma' kuramıyla onu büsbütün öksüz, gerçek varllğı olmayan bir kurum olarak nitelendirdi. Bu yüzdendir ki, Marksistler, bir şeye yanlış demezler, "metafizik!" der, işin içinden çıkar." (Karakoç, 2017a: 7). Metafiziğin tahrip edilişi ve medeniyet dairesinin kurulamayıșı, sanatsal üretimin kadük kalması sonucunu doğuracaktır. Karakoç, toplumun kültürel belleğinde metafiziği önemli bir ilke ve anlayıș olarak görür. Bu bağlamda Karakoç'un şiirlerindeki en önemli etki alanı metafizik olmuştur. Şairin şiir dili geliştirmesinde bu alanın önemine değinen Yıldız bu konuda şöyle bir tespitte bulunur: "Sezai Karakoç'u çağdaşı diğer şairlerden ayıran en önemli hususiyet, onun şiirlerinde metafiziğin esaslı bir yer teşkil etmesidir... Sezai Karakoç'a göre metafizik şiir için bir malzeme değil; şiirin kaynağıdır." (Yıldız, 2010: 566-567) Karakoç'un yazılarında da ifade ettiği bu durum, onun şiir poetikasını belirleme yönünde ciddi bir güce sahiptir. Metafizikte yaşanacak bir yabancılaşma ve tanım zorluğu medeniyet kimliğinin özgün kurulamayışına neden olacaktır. Metafizik kavramı üzerindeki kırılma, Allah ve ahiret inancını yerinden sarsıp seküler bir daire olarak dünyanın merkezileşmesi sorununu olgusal bir değere taşıyacaktır. Bu bağlamda din ise seküler bir alana hapsedilerek ibadetlerin öteki âlemden koparılması çerçevesiyle şekli bir tapınma ritüeline dönüşebilir. Karakoç, ahireti anlayamayanların bu dünyayı anlamasının da zor olduğunu düşünür: "Ölümü görmeyen, hayatı da yaşamamıştır. İslâm uygarlı̆̆l, temeli inanç olan hakikat uygarlığıdır. Onda üç ilkeyi yanyana ve içiçe görürüz: hayat, ölüm ve sonrası ilkelerini." (Karakoç, 2017a: 9). Karakoç'a göre akıl, fizikötesi inancını kaybeder 
ise seküler alanda sürüklenir kalır. Ruhun Mutlak’a dönük penceresi bir kere görülmek istenmemiş ise insan, akıl ve gönül penceresinden çok daha büyük sorunların içerisine yuvarlanmaktan kaçamayacaktır. Fizikötesi yaşamın merkezinde olmakla birlikte bu bakış açısını yitirenlerin asıl yoksullar olduğunu düşünen Karakoç, Rönesans'ın insanın ruhunu çölleştirdiğini ifade eder.

Karakoç, geleneğin bir izlek olarak sanat eserinin oluşumundaki etkisini önemli görür. Gelenek tarihin derinliklerinde kaybolmak anlamına gelmemekle birlikte şair, yeni olanı meydana getirirken geleneğin önemli fonksiyonu olduğunu düşünür. Bu durumda Eliot'un şairler üzerinde yaptığı değerlendirme de Karakoç'un poetikasıyla yakın ilişki içerisindedir: "Geçmişin 'hâl' içinde varlığını hissetmek kadar ebediyeti, sinırsızı, sinırlı olanda, yani bugünde bulmak, bu beraberliği hissedebilmek bir yazarı gelenekçi yapar." (Eliot, 2007: 3). Şiir ve gelenek ilişkisi bağlamında Eliot ayrıca şu yorumu yapar: "Yeni eserin, eski esere hiçbir yenilik getirmeksizin benzemesi bu gelenek anlayışının dışında kalır. Bu ölçüde bir benzeyiş, onu sanat eseri olmaktan uzaklaştırır. Ayrıca yeni eser, sadece geleneğe uygun olduğu için de değer taşımaz. Fakat onun gelenekle uyum halinde oluşu, değerlendirilmesinde bir ölçü olabilir." (Eliot, 2007: 4). Dolayısıyla Eliot üzerinden Karakoç’un şiiri okuma yoluna gidildiğinde, şiiri sadece geçmiş sarmalına kenetlenmiş bir ifade ediş biçimi değil, geçmişi bugünde hissetmekle alakalı bir poetik arayış olarak yorumlamak gerekir. Başka bir deyişle bu durum, geçmişte donup ardı ardına kopyalanan bir kaynaktan çok; dinamizmi kendinde daima var olan bir değerler sistemini de işaret eder. Geleneğin kültürel belleğini günümüze taşıyacak kişinin şair olduğunu ifade eden Karakoç, onu da şiire ilişkilendirenin gelenek olduğunu bilir. "Gelenek, şairi ilkin şiire götürendir. Şiiri sevme, daha evvelki şairlerle ruh ilişsisini kurmakla başlar şairde. Giderek, şiir şairin içine yerleşir, ruhunda yuva yapar. Şairin, şiire sempati duyması, sonra da şiirle yoğrulması, geleneğin ona ilk etkisi ve armağanıdır. Gelenek, şairin ilk dünyasıdır." (Karakoç, 2017a: 107). Şiir retoriği gelenekten beslenen Karakoç'un poetik tavrı Tanzimat'tan beri toplumu, düşünce ve kültürel kaynaklarını Batı'ya aitleyen, koruyan, yenilikçi aydın tabakasına karşı ontolojik bir içe kapanış şeklidir. Bu durum aynı zamanda geleneğin modern olanla çatışması olarak düşünüldüğünde; "Türk şiirinin kendi kaynaklarına dönme savaşıdır." (Karataş, 1998: 245) şeklinde yorumlanabilir fakat bu kaynağa dönme savaşı sadece Karakoç merkezinde bir vurgu değeriyle İkinci Yeni olarak adlandırılan şiir akımının dışında bir gelenek bulgulanışı durumundadır.

Şairin gelenekle karşılaşma anı eser meydana getirme sürecinin hazırlayıcı dönemine işaret eder. Karakoç'a göre geleneğin şair üzerindeki etkisi ve onu yola koyuşu varlık düzleminde bir sorgulama olarak değerlendirilir. Şair bu çatışmalar sürecinden sonra artık özgün bir metafizik duyuş ile üretmeye başlar ve böylece gelenek kendi içerisinden gelişimini tamamlamış olur. Karakoç'a göre şair, gelenekle hesaplaşmasında geleneği reddetme düşüncesiyle karşı karşıya kalsa da artık hızlıca terk edeceği o daireden yeni olana yürümek durumundadır. Ruhtaki bu yenilik "geleneğe karşı olmak değil, belki onun biraktı̆̆ noktadan başlamak demektir." (Karakoç, 2017a: 109). Bu durum Tanpınar'ın ifadeleriyle yorumlanacak olursa; “...ferdi kuvvetlerimiz ne kadar yüksek olursa olsun, hayatı kendimizden tam bir mevcudiyet gibi duymamı için bütün bir an'anenin yardımına bizden evvel hazırlanmış bir yığın terkibin bizimle beraber çalışmasına muhtacız." (Tanpınar, 2000: 65) görüşü sadece Batı düzleminde bir medeniyet dairesi kurmak değil, bugünü geçmişiyle ve en uç noktalarıyla birleştirerek terkip oluşturma şeklinde okunmalıdır. Hâlbuki Sezai Karakoç'un nesirlerinde işaret ettiği gelenek olgusunu işleme ve retorik olarak ifade etme biçimi, az önce Tanpınar'dan yapılan alıntıda ve belki bu anlamda cumhuriyet devri Türk şiiri değerlendirmelerinde öne çıkan gelenek olgusuna yönelik sadece teorik fikirler bağlamında kalmaz, bizatihi Karakoç'un şiir dilinde de pratik olarak varoluş alanı bulur.

\section{Gelenek ve Kökler}

Karakoç, geleneksel sürekliliğin büyük yıkım dönemi olarak Tanzimat'ı görür. Tanzimat ile birlikte başlayan edebiyatta köksüzlügün dünyaya güçlü eserler bırakamamak ile kendini gösterdiğini savunur. Karakoç'a göre Tanzimat ile birlikte kendi edebiyatını küçümseyen, medenî 
olmanın önündeki engelin edebiyatımız olduğunu düşünen, edebiyatımızın kadim değerlerinin yerine batılı muhtevayı getirenler bu yıkımın asıl sahipleridir. Çünkü bu modernleş(tir)me sürecinin baş amilleri "toplumsal kurtuluş ve kuruluş ideolojisine" bağlı kalarak; "geleneksel kurum ve siyasal, toplumsal referans ve meşruiyet kaynaklarının yerlerine modernleşmiş Batı dünyasınınkileri koymak anlamında" (Çetin, 2003: 37) bir değişimin önünü açmak niyetindedir. Dolayısıyla modernleş(tir)me adı altında uygulanan devrimsel hareketlilikler, toplumun siyasal anlamda demokratikleştirilmesinde, toplumsal anlamda ise bu sürecin diğer ayağını oluşturan kültürel değişimde, edebiyat ve retoriğinde kendisini hissettirmiştir. Karakoç, Tanzimat süreciyle başlayan gelenek kırılmasını şiir retoriği üzerinden yorumlarken bunun bir kıyım olduğu vurgusunu yapar: "Bu ülkede her anlama kyyıldığı gibi şiire de kıyllmıştır. Geçmişle ilgi kesilmiş, dünyanın en basit taklitçi şairleri büyük şair diye ilan edilmiş, bunların sonucu olarak da şiire karşı büyük bir ilgisizlik doğmuştur. Bir toplumun kalbini tazeleyen başlıca ruhî gıdalardan biri olan şiir böyle bir kurutuluşa uğratılınca, toplumun ölü hale gelmesi, bu açıdan da, uygarlığımızın düşmanları tarafindan oldu." (Karakoç, 2014: 9). Dolayısıyla Karakoç, edebiyattaki yoksulluğumuzun asıl kaynağının Tanzimat olduğunu düşünür. Yenilik iddiasıyla gelişim imkânı bulan Tanzimat edebiyatının kurucu iradesinin en temel hedefi ise, klasik edebiyatımızın kendi içerisinde gelişen yenileşme imgelerini yerinden etme düşüncesidir. Batı'nın sanayideki etkileyici gücünü referans alan Tanzimat'ın devlet idaresi, edebiyatımıza batılı kültürel muhtevayı da getirerek geleneğin ürettiği estetik ve epistemolojik birikimi batılı kavram ve anlayışlarıyla yeniden tanımlama yoluna gider. Karakoç bu bağlamda geleneğe bağlılığıyla Tanzimat'ın yıkıcılığının tam karşısında durmayı bilir. "Sezai Karakoç, İkinci Yeni içinde gelenekle en sağlam bağlantıyı kuran şair olarak anılır. Onun, daha ilk şiirlerinden itibaren gelenekle kurduğu irtibat, bütün şairlik serüveni içerisinde kendini önceleyen bir nitelik halindedir." (Akkanat, 2002: 103). Belirli bazı akımlara eklemlenmek istenen şair, evrensel derinliği ile kalıpların dışında kalmayı başarır. Çünkü Karakoç, merkezileştirici güç etkisinin modern toplum oluşturma çabası ve bu çabanın jakoben aydın kitlesi tarafından desteklenme sürecinin dışında kalarak kaynağını Doğu/İslâm birikim ve dinamiklerinden alan bir münevver tavrıyla toplumuna seslenir.

Geleneğin oluşum sürecinde "tarih", üzerinde dikkatle durulması gereken önemli olgulardan biridir. Millet kavramını ırk temelinde değil de tarihin birleştirici özelliğinde arayan şair, Türk milletini bin yıldan daha uzun bir zamanda varlığını devam ettiren millet olarak tanımlar. Karakoç, Osmanlı dönemini bir millet dönemi olarak tanımlarken millet olmayı mükemmele yaklaştırarak; edebiyatıyla, ahlâkıyla, yönetim, sanatı ve birçok yönüyle benzerine rastlanmayan bir özellik olarak gösterir. XIX. yüzyılda Batı'da gelişip ülkemizde ulus kavramıyla ortaya çıkmış tanımlamaları külliyen reddeden şair, İslâm medeniyet dairesindeki millet kavramını medeniyetin organik bir yapısı olarak görür. "Ümmetle millet ayn realitenin iki yüzüydü. Bunu anlamayanlar, bugün o çağa "ümmet” çağı deyip geçiyorlar. "Ümmet”, (...) İslâm kültür ve medeniyet toplumlarının sübjektif adl, "millet", objektif adıdır. Bugün sadece trk ve dil esasina dayanan millet teorileri iflâs etmiş, bu yüzden yeni yeni içerikler aranılmaya başlanmıştır." (Karakoç, 2017b: 17). Dolayısıyla amaç birlikteliği, zaman ve mekândan farkl1lık gösteren insanoğlu için kadim köklerini belirli bir dinî veya kültürel fundamentalitede aramak yerine, Karakoç'un izini takip ettiği Hanif bir insanlık geleneğinin Hz. Adem'de bilgi arayışını dışarıda bırakmayan, Hz. İbrahim'in yüz çevirdiği dünyevî mabetlere yaklaşmadan, Meryem'in masumiyetini görmezden gelmeyerek ve Hz. Peygamberin putperest bağnaz toplumundan farklı bir uygarlığa, evrensel ve tevhidi bir değere işaret eder.

Şair, millet olmanın temel şartlarından birinin de kendine ait bir edebiyatı olmaktan geçtiğini savunur. Kültür ve medeniyetin birlikteliği üzerine dikkat çeken Karakoç, medeniyetlerin de edebiyatlarını ürettiklerini ve bunun da millet olmanın yolunu güçlü kıldığını düşünür. Kültür gibi edebiyatın da kendi medeniyet dairesinden beslenmesi gerektiğine inanır. Edebiyatın kaynağını Türk insanının duyuşu, anlayışı, acıları ve sevinçlerinin oluşturması gerektiğini ifade eden Karakoç, tüm yönleriyle insanının eserlerde konu edilmesini arzu eder. Edebiyattan millete, milletten edebiyata 
dönüşümün estetik değerleri güçlü kılacağı aşikârdır. Böyle bir gelişim süreci faydayı sadece kendi coğrafyamızda değil tüm insanlığın ortak faydası olarak gösterecektir. Karakoç, edebiyatın kaynağının hakikatten beslenmesi gerektiği fikrini merkeze alırken edebî yapıtın gücünün hakikat kavramı ile ilişkisine de vurgu yapar.

Karakoç, Batı kaynaklı nasyonalizm etkisi ile edebiyatımızın klasik dönem ile irtibatının zayıfladığını savunur. Metafizik merkezli üretim geleneği ile bağlantısını kaybeden sanatçı, batılı muhteva ile yabancı bir dairenin zihinsel devinimi alanına savrulur. Bu savrulma edebiyatımızda klasik şiirin biriktirdiği hikemi söyleyişi de sanatkârımız için yabancılaştırır. Bu yabancılaşma epistemolojik kopuş olarak kendini Tanzimat metinlerinde gösterirken edebiyatta kargaşa kaçınılmaz olur. "Artık düşünceler, geçmişsiz ve geleceksiz, havada ve askıdadır hep. Toplumun sessiz ve görünmeyen yanı, iç gerçeği ve yaşantısıyla ilgisiz bir takım şurdan burdan derlemelerden ibarettir artık düşünce ve sanat.” (Karakoç, 2017b: 19). Tanzimat ile birlikte yerinden edilmeye çalış1lan divan şiiri, dönemin yenilikçi zihni tarafından geri kalmışlı̆̆ın ana sebebi olarak görülür. Ahmet Atillâ Şentürk ise aynı şekilde bu durumu eskiyi yıkma eğilimi içerisinde bulunan aydın grubuyla ilişkilendirerek şöyle yorumlar: "XIX. ve XX. yüzyıllarda Türklerin yaşadıkları yoğun bir batılılaşma süreci içerisinde eski şiir gelenekleri neredeyse tamamen unutulmuş, şiir ve edebiyatla uğraşan kimselerin dahi eski şiirin iç dünyasına yabancı kaldıkları ve onu anlamakta zorlandıkları bir dönem başlamıştı. (...) Bu arada Osmanlı devletinin yıkılması ve Türkiye Cumhuriyetinin kurulması ile yeni bir edebiyat ve kültür oluşturmak için eskiyi tamamen ylkmak ve ona cephe almak gerektiği düşüncesindeki bazı aydınlar, eski kültüre ve özellikle eski şiire karşı olumsuz kanaatler besleyerek yoğun bir aleyhte kampanya başlattılar." (Şentürk, 2004: 59). Dolayısıyla Türk modernleşmesinin temel yapıtaşını oluşturan yenileşme ve bu süreçle birlikte kültür ve medeniyet dairesindeki değişim, eski ve eskiye ait olan bütün dinamiklerin yerinden edilmesi anlamını taşır. Bu bağlamda gelenekten beslenen ve ilhamını bu kaynaktan alan Karakoç, çağcıl yazar ve şairlerinden ayrışan kimliğiyle; "Tanzimat'tan sonra kaybedilen/yitirilen devamlıllğın yeniden kurulması" (Ayvazoğlu, 1997: 205) anlamında, geçmişin bütün kültür ve gelenek olgularını bütünleştirerek çağa sunmuş, salt modern ve onun yapıtaşlarına karşı medeniyet dairesindeki bütün uç noktaların terkibini oluşturmuş şahsiyettir.

Yine şiirimizin tarihi bakımından Yahya Kemal'in divan geleneğimize ve eskiye dikkat çekmiş olması da Karakoç bakımından değerlendirmeye muhtaçtır. Karakoç, Yahya Kemal'in klasik şiiri merkeze almaya çalışıyor oluşunu değerli bulsa da bunun divan şiirine yeni bir can suyu olduğu görüşünde değildir. Hatta Yahya Kemal'in şiirinin batılı formasyona sahip olduğunu söyleyen Karakoç; Tanzimat sonrası bazı sanatkârların edebiyatımızı klasik edebiyat ekseninde yenileme çabalarının sonuç vermediğini düşünür. Buna mukabil Karakoç, geleneğe sırtını dayarken geleneğin içerisinde kendini tekrar etmeyerek şiirini canlı ve yeni tutmayı başarır. Karakoç, gelenek ile modernite arasında nevi şahsına münhasır bir alanı inşa etmeyi başarır.

Karakoç’ta din ile sanat ilişkisi bahsi de üzerinde hassasiyetle durulması gereken önemli konulardandır. Bu iki kavramın birbiriyle ilişkisi üzerine değerlendirmede bulunan Karakoç, dinin sanata kaynaklık etmesi gerektiğini temel ilke olarak görür. Aksi halde iki kavram arasındaki sakat ilişki Hıristiyanlık örneğini bizlere hatırlatacaktır. "Hıristiyan sanatında, önce sanat, din için kullanılmak istenmişse de, giderek, din, sanat tarafindan kullanılmıştır. Bu eğilim Tolstoy ve Dostoyevski ye, hatta günümüz sanat ve edebiyatına kadar devam eder. Kur' ân-ı Kerim 'in "şairler" sûresinde değinilen nokta, aslında bu değil midir? Dinle sanatın ilişsisi. Yunan mitolojisi ve Arap şiirinden tutun da Incil şairlerinin, dini, sanatları uğruna hoyratça harcamalarına işaret yok mu onda? Sanat, Kur'an'da, asliyle belirtilmiş, fakat sınır tanımazlığındaki tehlikeler de gösterilmiştir. Sağllklı sanatın çizimidir bu." (Karakoç, 2017a: 17). Sanat ve dinin birbirine girmiş olduğu Batı toplumlarındaki örneklerde soysuzlaşma görülürken İslâm medeniyetinde bu iki kavramın birbiriyle ilişkili fakat bağımsız kurumlar olarak görülmüş olması güçlü bir sanat dünyasının oluşumunu mümkün kılar. Karakoç'a göre İslâm medeniyet dairesinin üretmiş olduğu sanata ilişkin bu müktesebat Rönesans sonrası Batı'da oluşmuş birçok metne güçlü tesirlerde bulunur. Bu bakımdan 
Karakoç'un nesirlerinde ele aldığı gelenek, söz konusu İslâm medeniyetinin devam etmiş kıymetlerinin çağımız adına diriliş şartlarını hangi metotla ele aldığına doğrudan işaret etmesi bakımından önemlidir.

\section{Sonuc}

Rönesans ile Batı; “doğa, insan ve Yaratıcı" üçlü geleneksel anlayışından Yaratıcı'nın dışarıda bırakıldığı, aklın tek belirleyici unsur haline getirildiği bir modernleşme evresine girer. $\mathrm{Bu}$ modernleşme dönemi ile dünya, doğa ve insanoğlu ile birlikte sadece pozitivist eksende okunmaya çalışılır. Sanayisindeki etkileyici gelişme ile kendi değerlerini tartışmaya açtırmayan Batı, tüm medeniyetler üzerinde dönüştürücü etkiye sahip olmak arzusuyla hareket eder. Osmanlı toplumunda da bu bağlamda büyük kırılma Tanzimat döneminde yaşanır ve geleneğin tüm unsurları tartışma zeminine çekilerek tezyif edilmeye çalış1ır. Modernleşme söylemiyle devlet idaresinin ve devrin aydınlarının eli ile kadim değerlerin yerinden edilmesi amacıyla yürütülen bu dönüşüme, belirli dönemlerde sanatkârlar itirazlarını yükseltir. Karakoç, politik ve kültürel şartların Tanzimat devri şartlarıyla benzerlik gösterdiği bir dönemde modernleşme sürecine özgün bir itirazı ortaya koyar. Aklın karşısına dini, moderniteye karşı geleneği, modernleşmeye karşı diriliş düşüncesini ortaya koyan Karakoç özgün bir duruş sergiler. Karakoç, geleneğin yenilenerek devamlılık gösterebileceği vurgusuyla tarihi, ulus düşüncesinin çok daha ötesinde millet kavramı olarak okumasıyla, geleneğin yenilenen boyutunu mekân ve zamanın ötesinde yeniden kurmayı bilir. Şair, modernitenin kesintiye uğrattığı geleneksel yenilenmenin imkânlarını ortaya koyarken hakikat fikrini de medeniyetinin merkezine metafizik bakış açısıyla getirir. Karakoç’ta gelenek, asıl olana dönüş ve İslâm medeniyetinin yeniden ihya ve inşa sürecine işaret eder. Şiiri hakikatin sesi olarak gören Karakoç millet olmanın temel şartlarından birinin de kendine ait bir edebiyata sahip olmak olduğunu ortaya koyar. İslâm mütefekkiri olarak Sezai Karakoç değişimi esas alırken merkezine diriliş fikrini konumlandırır. Toplumsal dönüşüm sürecinde Karakoç için; diriliş, medeniyet, kültür, ilerleme, metafizik, zihniyet, din, batılılaşma, İslâm gibi kavramlar anahtar kavramlar olarak görülebilir.

\section{Kaynakça}

Akkanat, C. (2002). Gelenek ve İkinci Yeni Şiiri. T.C. Ankara: Kültür Bakanlığı.

Ayvazoğlu, B. (1997). Geleneğin Direnişi. İstanbul: Ötüken Yay.

Çetin, H. (2003). Gelenek ve Değişim Arasındaki Kriz: Türk Modernleşmesi. Doğu Batı Dergisi, Y. 7. S. 25.

Eliot, T. S. (2007). Edebiyat Üzerine Düşünceler. (Çev. Sevim Kantarcığlu). İstanbul: Paradigma Yay.

Karakoç, S. (2014). İslâm'ın Şiir Anıtlarından. İstanbul: Diriliş Yay.

Karakoç, S. (2017a). Edebiyat Yazıları I, Medeniyetin Rüyası Rüyanın Medeniyeti Şiir. İstanbul: Diriliş Yay.

Karakoç, S. (2017b). Edebiyat Yazıları II, Dişimizin Zarı. İstanbul: Diriliş Yay.

Karataş, T. (1998). Doğu'nun Yedinci Oğlu Sezai Karakoç. İstanbul: Kaknüs Yay.

Polat, A. (2018). İkinci Yeni Şiirinin Felsefi Kaynakları. İstanbul: Kesit Yay.

Şentürk, A. A. (2004). Osmanlı Şiirinde “Aşk”” Dair. Doğu Batı Dergisi, Y.7. S. 2.

Tanpınar, A. H. (2000). Edebiyat Üzerine Makaleler. İstanbul: Dergâh Yay.

Yıldız, A. (2010). Tanzimat Sonrası Türk Şiirinde Tasavvuf. Turkish Studies, Volume 5/2. Spring, 526-572. http://dx.doi.org/10.7827/TurkishStudies. 1112 